\title{
1. Origins, diffusion and development of the Ecological Footprint
}

\section{THE ORIGINS OF THE ECOLOGICAL FOOTPRINT}

The Ecological Footprint has stimulated an enormous amount of academic and policy attention since its initial inception in the early 1990s. Van den Bergh and Grazi (2010) report that the Institute for Scientific Information (ISI) Web of Knowledge delivered over 500 journal articles for 'ecological footprint', with an increasing trend from 2001 to 2008, while the Google search engine delivered more than 2 million hits and Google Scholar more than 14000 hits for 'ecological footprint'. This is an impressive rate of activity since the first academic article on the concept of the Ecological Footprint was published in 1992 (Rees 1992). Initially Professor William (Bill) Rees, who along with Mathis Wackernagel (his former PhD student) is most frequently associated with the Ecological Footprint, did not use the term but instead referred to 'regional capsule' and 'appropriated carrying capacity' (Rees 1992). It was only later that Rees coined the term 'Ecological Footprint' when critiquing economic models of resource use, arguing that more attention should be paid to the land area required by urban areas to sustain themselves.

Rees has described how he drew upon the biological notion of carrying capacity when developing the idea of an Ecological Footprint (see Gismondi 2000). Carrying capacity is typically defined as the maximum population size that can be supported indefinitely by a given environment (Hixon 2008). The term 'carrying capacity' is however problematic because empirically it is not a constant but will vary, for example, due to fluctuations in the climate. For this reason, carrying capacity has a greater theoretical utility value than practical value for ecologists (Hixon 2008, 
p. 530). For Rees, though, it was not so much the practical challenge of trying to interpret human resource use in the language of carrying capacity that was problematic, it was the critique of economists who pointed out that the term had little value for the analysis of human consumption. This was for two reasons. First was the possibility of trade between areas: if an area is experiencing a shortage of one product this means that it can then be imported from another area, whilst a surplus can be exported to an area that demands it. The other challenge from an economic perspective to basing a resource tool on carrying capacity was that it failed to account for technology: when goods or services, whether these be man-made or natural, are in scarce supply it creates an ever greater incentive to provide a substitute. Technological innovations can overcome resource scarcity by enabling more efficient use of those resources or delivering a substitute for them. To meet the objections of economists, Rees reformulated the question of carrying capacity. Instead of asking the ecological question of 'What are the number of organisms per unit area?' he asked the Ecological Footprint question of 'How much area is needed per organism per population?' (Gismondi 2000).

By posing the question of how much land is needed to meet the consumption demands of individuals, or a defined population or activity, the advocates of the Ecological Footprint reframe environmental policy debates away from those predicated upon growth, such as weak forms of sustainable development, Factor Four (von Weizsacker et al. 1997) or ecological modernisation (see Hajer 1995; Mol 1995, 2001; Mol and Sonnenfeld 2000), to one where environmental limits are to the fore. This is because Rees and other advocates of the Ecological Footprint estimate that globally there are less than 2 hectares per capita of productive land and water area, and according to the World Wide Fund for Nature's (WWF's) Living Planet Report (LPR) those who live in the wealthier countries use between 4 and 12 hectares per capita per year (see WWF 2014). With those living in the developing world seeking to improve their standard of living towards that of the West, and as the world's population continues to grow, then the demands placed on the Earth's resources will continue to increase. Rees clearly expressed the problem as: 'you can't bring 9 billion people to the same material standards that we enjoy with anything like the kinds of technologies that we are using or are likely to emerge or be made 
available particularly in the developing world in the next 40 years' (Gismondi 2000). Similar sentiments are echoed from an ecological perspective, where it is recognised that 'the carrying capacity concept is clearly of heuristic value given the fundamental truth that no population can grow without limit, and especially given the fact that many human societies have behaved as if no limits exist' (Hixon 2008, p. 530).

\section{THE RISE TO PROMINENCE OF THE ECOLOGICAL FOOTPRINT}

In this section, we briefly introduce two key concepts that have frequently been presented as alternatives to the Ecological Footprint, namely Environmental Space and the Ecological Rucksack. Neither has gained the popularity of the Ecological Footprint. Interestingly the Ecological Footprint emerged onto the international stage at a similar time to that of the concept of Environmental Space (Opschoor and Reijinders 1991; Carley and Spapens 1998), but their fortunes have subsequently diverged markedly. Both the Ecological Footprint and Environmental Space, and related terms such as the Ecological Rucksack, have been devised to link consumption to resource use (Carley and Spapens 1998, p. 70). Within these different methods there is a desire to ask whether current patterns of resource use are sustainable and equitable. For these approaches the answer is clearly no, but they arrive at their conclusions in different ways. According to McLaren et al. (1998, p. 6): 'Environmental space is the share of the planet and its resources that the human race can sustainably take. Or in other words, the share of the Earth's resources that humanity can use without depriving future generations of the resources that they will need'.

Environmental Space identifies a number of resources that are key for production and consumption, including energy, strategic non-renewable resources (for example, pig iron for steel, cement), fresh water, woodlands, land use providing living space and a source of renewable resources (for example, food production) (Carley and Spapens 1998, p. 61). For each of these resources an assessment is then made of their exploitation (usually over a year) by humans without harming the quantity and quality that can be 
used by future generations. So, whereas the Ecological Footprint converts the impacts of resource use into a single unit (the global hectare) (gha), the Environmental Space method provides a separate measure of each of the key resources. As the advocates of Environmental Space admit, "it is the more complex approach ... it is also probably more difficult to understand and communicate' (Carley and Spapens 1998, p. 70).

The concept of Environmental Space was most widely discussed in the Netherlands (see Hille 1997). The term gained much broader international currency with the publication in English of the Action Plan for a Sustainable Netherlands (Buitenkamp et al. 1992) by Friends of the Earth (FoE) Netherlands. The Action Plan is an effort to quantify the amount of Environmental Space for some major resources that will be available to each Dutch resident in 2010. The Action Plan prompted similar efforts in other countries, most notably a pan-European perspective, Towards Sustainable Europe (Spangenberg 1995), carried out by the Wuppertal Institute in cooperation with Friends of the Earth Europe. There is perhaps only one significant example of the application of the Environmental Space approach in the UK, that of McLaren et al. (1998). Part of the reason for the different experiences of the Ecological Footprint and Environmental Space approaches is that the latter is targeted at national government, whereas the former has most often been promoted to local government where there can be more sympathy for innovative tools, and it has much more flexibility in its application.

The idea of Environmental Space is operationalised through the measurement of material inputs. These are the sum of problems associated with materials consumption (for example, physical disturbance, pollution, waste disposal) and can be roughly related to the total amount of materials moved in the course of economic activity (Hille 1997). Materials include the earth that must be moved to get to resources and the extraction of those resources to make products. Finally, material input analysis includes the economically worthless materials that have to be moved in the course of construction activities, and materials unintentionally moved in the course of economic activity. In a further refinement of the materials input approach is the Ecological Rucksack. The Rucksack calculates what would normally be hidden behind our material inputs as it includes all of the resources used in our 
consumption of a particular material (Hille 1997). Rather like a more sophisticated and comprehensive form of life cycle analysis, research on the Ecological Rucksack has concentrated on products but has also gone further to compare different ways of consuming foods, for example ready meals versus home-prepared food (Sonesson et al. 2005), and been used to critique the Carbon Footprint (Burger et al. 2009; Giljum et al. 2011).

Although Environmental Space and the Ecological Rucksack have their advocates and show considerable methodological sophistication, they have not gained the same prominence as the Ecological Footprint (see Table 1A.1 in the Appendix to this chapter for a timeline of key events in the Ecological Footprint storyline). In part this is because, as the case of the UK shows, the Ecological Footprint has had a number of applications, including products, organisations, services, and at different levels of government (Chambers and Lewis 2001; BFF 2002a; Barrett and Scott 2003; Barrett et al. 2005c; Collins et al. 2005). More than that, though, the Ecological Footprint has had policy entrepreneurs who have championed its case. These entrepreneurs have been able to promote the Ecological Footprint to a wide range of policy audiences and to promote it as a way of helping to improve the quality of decision making by ensuring that more attention is given to the environmental consequences of policies. In the section below we briefly review Kingdon's (1984) policy model and its usefulness in helping to understand the rise to prominence (and subsequent demise) in public policy agendas of the Ecological Footprint.

\section{POLICY CHANGE AND THE ECOLOGICAL FOOTPRINT}

Kingdon (1984) proposed a Multiple Streams Framework (MSF) to explain how agenda-setting occurs. Policies change (or remain stable) according to the extent to which a series of independent streams conceived of as problems, policies (solutions) and politics come together. Boezman et al. (2010) have also drawn upon Kingdon's work to explore the waxing and waning of the Ecological Footprint in Dutch policy making. The MSF theorises that the coupling of these streams at critical junctures results in the greatest potential for public policy agenda change. The MSF is 
helpful for understanding how the Ecological Footprint has become legitimised in public policy because it attaches problems to policies. Policy agendas do not change because of an objective and rational search for solutions to policy problems. Rather, solutions compete with one another, and much depends on how problems and their solutions are constructed in policy arenas. As Boezman et al. (2010, p. 1757) note, 'Policy processes are as much structured by ideas, causal stories and beliefs as they are structured by institutions'. Moreover, the MSF is helpful because it highlights the part that may be played by key organisations who advocate the Ecological Footprint such as WWF and Global Footprint Network (GFN) and policy entrepreneurs such as Mathis Wackernagel in promoting policy change.

Policy entrepreneurs play a key part in the MSF model as they are able to bring together policies, problems and politics to advance their favoured policy option. Kingdon (1984) recognised that a small number of highly motivated actors exercise a significant ability to build coalitions of support for their ideas and secure policy change. These policy entrepreneurs tend to share a number of characteristics, including the identification of an alternative policy or approach and a drive to promote change; an assertion of legitimacy, such as scientific expertise (the Ecological Footprint is promoted as a technically sophisticated model) or the ability to speak on behalf of others (Wackernagel is the leading figure and founder of GFN, the network organisation that promotes the use of the Ecological Footprint and standardises its methodology; see Chapter 6); and, because of their credibility, policy entrepreneurs often have access to political and policy elites (for instance, Wackernagel has worked with the Environment Protection Authority Victoria in Australia (EPA Victoria); see Chapter 4), and with the United Arab Emirates (UAE) Ministry of Environment and Water (see Chapter 3); and the work of policy entrepreneurs can be linked to organisations that wish to show that they can provide leadership. For example, the Welsh Government, a devolved governmental body in the UK (created in 1998), has from the outset wanted to show that its legislative responsibility to promote sustainable development in all of its activities has made it different from other legislative bodies. It has thus been sympathetic to using the Ecological Footprint as one of its headline indicators for measuring progress towards sustainability (Flynn 2010). Similarly, in Australia 
the Environment Protection Authority Victoria (EPA Victoria) has made much use of the Ecological Footprint (see Chapter 4). Finally, policy entrepreneurs are successful at defining problems, highlighting problem attributes and formulating credible policy solutions; what Kingdon calls a policy stream. Policy streams are the way in which issues become topics of public policy concern, and the way in which they are defined.

The Ecological Footprint has further reinforced the concerns raised by environmentalists and scientists regarding the extent of environmental degradation. WWF's biennial LPRs, the most recent one being published in 2014 (WWF 2014), provide an overview of the biocapacity and resource use of countries and how that has changed over time. The message that emerges is that biocapacity is declining and resource use increasing, but that it is doing so in a highly differentiated way. Some countries are major users of resources, such as Qatar and the UAE; whilst industrialisation, urbanisation and a growing middle class are fuelling enormous increases in consumption in China, so that although China has a low Ecological Footprint per capita, at a national level it is large and on an upward trajectory. In 2008, China's Ecological Footprint per capita was 2.1 gha, lower than the global average of 2.7 gha, but its total Ecological Footprint was 2.9 billion gha due to its total population and per capita footprint (WWF China 2012). The use of data over time and between countries enables comparisons to be made, questions to be raised, and for the nature of continuing on current development paths to be problematised. Thus, a major environmental problem becomes defined as one that demands action from governments.

So far in this chapter we have explored how policy entrepreneurs identify policy problems and provide policy solutions. In Kingdon's model, how problems are defined is also important. The timing of the rise of the Ecological Footprint to public policy prominence in the 1990s, and then its demise from the mid-2000s onwards (see Chapter 5), is tied into wider environmental and sustainability debates. Through the 1980s and particularly in the 1990s a series of high-profile summits, such as the United Nations Conference on Environment and Development in Rio (1992) and the World Summit on Sustainable Development in Johannesburg (2002), and growing concern with climate change, such as the United Nations 
Environment Programme and the World Meteorological Organization establishing the Intergovernmental Panel on Climate Change (1998), and the adoption of the Kyoto Protocol (1997), meant that there was widespread recognition of the scale and significance of environmental change. Debates on sustainable development, which often sought to connect local consumption with global impacts, could combine with climate change debates that drew attention to resource limits in the Ecological Footprint. Here was an indicator which was based upon the finiteness of the Earth's resources and could show how individuals, cities or countries were consuming or overconsuming their share.

According to Boezman et al. (2010, p. 1757), policy actors are engaged in a process of continuous communicative interaction in which ideas and arguments are being tested and reformulated. Drawing upon the work of Kingdon (1984), Boezman and his colleagues point out that experts, bureaucrats, academics and advisors rework scientific insights into new policy concepts, of which the Ecological Footprint and its variants such as the Carbon Footprint and Water Footprint make good examples. Those involved in the policy process spend a considerable amount of time and resources promoting their favoured concepts, so that when a policy window or opportunity opens up they can manoeuvre their concept into a leading position as a policy solution.

In their work on the transfer of the Ecological Footprint into Dutch environmental policy, Boezman et al. (2010) also point out that the way in which a policy issue is framed may impact upon its use. They distinguish a number of features that a policy concept may hold. First, and perhaps one of the most important for our purposes, is the quality of the scientific knowledge behind the concept. GFN has recognised the importance of scientific validity and has sought to demonstrate the robustness of the Ecological Footprint through publications in peer-reviewed scientific journals (see Chapter 5) and standardising the methodology (see Chapter 6). Critics of the Ecological Footprint have similarly recognised the claims that can be made by a scientifically valid concept, and have sought to undermine its method (see, for example, Van den Bergh and Verbruggen 1999; Lenzen and Murray 2001; Ferng 2002; Van Vurren and Smeets 2001; McDonald and Patterson 2004; Moffatt 2000; van Kooten and Butle 1999; Ayres 2000; Herendeen 2000; McGregor et al. 2004). Second, there is the fit between the 
normative claims made by a concept, and existing value systems. Central to the Ecological Footprint are claims of resource limits and fair share of the Earth's resources. At a time of widespread prosperity in the West, rethinking models of economic growth (see, for example, Anderson and M'Gonigle 2012; Beder 2011; Illge and Schwarze 2009) can have some appeal. The onset of recession in 2008 makes more traditional models of growth more attractive, and arguments for 'sustainable growth' move to the fore. A third feature is the rhetorical quality of a concept (Hannigan 2006). The Ecological Footprint strikes a resonant chord with the public and policy makers; it makes complex problems understandable and communicates the scale of the environmental challenge. As we argue below, the Footprint has considerable metaphorical power.

By applying Kingdon's (1984) MSF, Boezman et al. (2010) compare the fates of the Ecological Footprint and Environmental Space (Boezman et al. call it the Environmental Utilisation of Space, EUSA) in Dutch environmental policy. Both concepts portray natural systems as providing a boundary condition for societal development. EUSA measures material flows that an economy can extract from the environment and return as waste. EUSA disaggregates its data by sector, whilst the Ecological Footprint turns all resource usage into a single measure, the hypothetical global hectare. EUSA was championed by an academic entrepreneur, J.B. Opschoor (Opschoor and Weterings 1994), but never received the recognition of the Ecological Footprint. In explaining the rise of the Ecological Footprint to policy prominence in the Dutch environmental policy between 1998 and 2006, Boezman et al. (2010, p. 1762) draw upon three contextual factors. The first of these is the way in which wider environmental policy debates were focusing upon resource depletion. Second, there was a set of agency variables which involved the lobbying practices of non-governmental organisations (NGOs) and the importing of expertise from GFN. As Boezman et al. (2010, p. 1762) explain:

NGOs invited Wackernagel to the Netherlands (1999) and gave him the opportunity to present the Ecological Footprint repeatedly to audiences of experts, civil servants, scientists and others involved in the environmental policy and advisory field. The involvement of Wackernagel himself and the echoes of his involvement in the RIVM [National 
Institute for Public Health and the Environment] publications decisively endorsed the Ecological Footprint's scientific credibility.

A further boost to the legitimacy of the Ecological Footprinting in the Netherlands was its endorsement by the Environment Minister Pronk. Third, there was a set of issue-specific factors, particularly related to the Ecological Footprint's rhetorical qualities and the imagery that it conjured up. The Footprint was considered to have had widespread appeal in the Netherlands (and elsewhere) because it 'succeeded in bridging the gap from scientific ecological knowledge to the (policy) public in what initially appeared to be a consistent and easy-to-understand way' (Boezman et al. 2010, p. 1762).

In the demise of the Ecological Footprint it was agency variables that proved to be of major importance. For instance, from early on there were robust critiques of the Ecological Footprint by wellrespected scientists such as Van den Bergh and Verbruggen (1999). Official environmental advisory committees also pointed to weaknesses in the methodology (Boezman et al. 2010). In a similar way to that of the UK, the Ecological Footprint was only able to temporarily 'fix' itself to the mainstream Dutch environmental policy agenda. The reasons why the Ecological Footprint may not become firmly fixed on policy agendas can be complex, and this is discussed in more detail in Chapter 4 when we explore how the Ecological Footprint has developed in the UK, and bring together local and national agendas and the roles of different professional interests.

\section{THE ECOLOGICAL FOOTPRINT AND POLICY DEVELOPMENT}

Having looked at how the rise of the Ecological Footprint can be linked to the way in which the policy process works, in this section we explore in more detail how the Footprint may contribute to policy development. First, we assess the ways in which knowledge and expertise can contribute to policy making; and second, we examine how environmental indicators may help to shape policy, but also how expert-led systems, which typifies the Footprint experience, can quickly become marginal to policy development. 


\section{Knowledge, Expertise and Policy}

There is widespread recognition that environmental issues tend to be marginalised in decision making (Hertin et al. 2009). A prime motivation of those involved in promoting the Ecological Footprint is that it should inform the policy process, and therefore bring knowledge on the scale of environmental change to the attention of decision makers. In their thinking on how they may contribute to policy development, Ecological Footprint practitioners are engaging in debates on how environmental knowledge is used, and as discussed below, working with a very particular view of the policy process.

Rayner (2003, p. 164) has characterised contemporary policy making as taking place in the 'age of assessment'. He notes (ibid.) that there is a ' $[\mathrm{g}]$ rowth in the reliance on ... assessment techniques has been accompanied by an expansion of expertise to design, operate and interpret such tools'. This is certainly true of the Ecological Footprint, where interest in its use grew dramatically (see, for example, Chapters 3, 4 and 5). At the same time there was the emergence of a set of elite actors able to undertake sophisticated Ecological Footprint analyses (in the UK this included Best Foot Forward, BFF; and the Stockholm Environment Institute - York, SEI-York) and to bestow legitimacy on Ecological Footprint studies (for instance GFN; see Chapter 6).

Appraisal, or a tool like the Ecological Footprint, is presented by its proponents as an objective practice, 'valued for its scientific authority' (Clark and Majone 1985, p. 16). Drawing on the work of Owens et al. (2004), Adelle et al. (2012) describe traditional forms of appraisal in which a 'technical-rational model' is based on a positivist epistemology. Here an 'objective appraisal' leads straightforwardly to 'better' decisions via instrumental forms of learning. Instrumental learning is that in which knowledge directly informs decisions because it provides specific information (that is, information that is relevant to a particular time and place). This can be contrasted with conceptual learning, in which knowledge gradually challenges existing belief systems or identifies new ideas; and strategic learning, in which knowledge is used in a more overtly political way to support or challenge existing positions. For the latter, knowledge can often have a symbolic value and a power to legitimate actions (see Waylen and Young 2014; Hertin et al. 2009). 
A common argument for the adoption of assessment techniques is their transparency: that it becomes clearer how decisions have been made and how judgements have been formed. An interviewee ${ }^{1}$ commented:

My key clients are who I would call decision makers or people who help, decision support officers I suppose ... So my idea is that the position that the person ... is not important ... [W] see council officers, civil servants, we see that we are offering them help in formulating policy and offering support to provide numbers to the policies which they may or may not put forward to [politicians].

There is, though, an alternative and more critical perspective on the Ecological Footprint. Key data is the preserve of consultancies and they protect it. This enables consultants to gain repeat business through new Footprint studies but can make it difficult for analysts to understand how the Ecological Footprint results have been derived. As one critical commentator pointed out: 'By offering no transparency in how it [the Ecological Footprint] is calculated, how it's done, offering no explanation of the assumptions behind it, you can't even tell where the data has come from, and so people have to go to them [consultants] again if they want an update'.

Nevertheless, the belief is that by providing information to decision makers that they would not otherwise have had, a fuller picture is provided of the implications of any decision. However, what may count as a more comprehensive data set to help inform decisions is not straightforward. At a normative level, Footprint advocates wish to increase the information on offer to decision makers but are also able to recognise that in practice information can be used selectively. As one practitioner interviewee explained:

What we highlight is its [the Ecological Footprint] use as a decision support tool and that's what we sell it as more than anything. We have also tried to suggest that it is organic and dynamic in its approach ... to give the user the ability to identify with the tool on their own personal terms; they can add their own perspective into the tool, where they got the data from, what they think of the components ... So it's about the user being able to identify with the tool and have some sense of ownership over it and this was so important to us.

Most commentators argue that the rational-technical model sits alongside more deliberative policy styles in which actors pursue 
multiple goals and policy appraisal becomes a means to support arguments or deflect critical attention. Information arising from an appraisal or an Ecological Footprint study would not be expected to directly transfer into policy or decision making (Owens et al. 2004; Adelle et al. 2012).

Ecological Footprint practitioners recognise that they are working in a complex policy arena. When one consultant was asked what difference their Ecological Footprint studies had made, the response was very cautious:

For its [the Footprint's] impact on policy and strategy, there may be someone in the council who likes it, who tries to use it on something or quoted it to a politician. But I don't think it actually changed policy. In [name of another local council] it is going to be included in the strategy [but] that doesn't really mean anything unless you're going to act on it, but the foundation is there as they are not frightened of it. And in the future, when they come to recalculate they'll be ready for the idea. I have no knowledge at all that [name of local council] are going to use it as an indicator. [Whilst for another council the] Ecological Footprint is an indicator that [name of local council] have got it on their list.

To put the Ecological Footprint on an environmental indicator list was, however, dismissed by the interviewee as a minimal commitment.

In addition, as Hertin et al. (2009, p. 1197) have pointed out, often an assessment report is used to justify a specific measure on the basis of its superiority to alternative courses of action. For the Ecological Footprint this is a major challenge. This is because the Footprint questions the basis of existing policy since it assumes the existence of environmental limits and economic constraints. This means that in pro-growth political systems the Ecological Footprint as a tool to analyse policy or contribute to policy development will often find itself on the margin. Footprint practitioners recognise the dilemma that they face, and as one explained:

We try to be as objective as we can but at the same time we had to make changes in [name of] report because we were told they were too controversial. Now you may say 'oh you may sell out if you make those changes' but the response from the Steering Group was if you don't make those changes then the credibility [of the overall report will suffer], people will turn off because they will see this as too radical. 
Advocates of the Ecological Footprint believe passionately in the value of the Footprint as a tool to aid better decisions, and also of the need to raise the status of the environment in decision making. To cope with a situation in which their findings can be marginalised, practitioners act as policy entrepreneurs, seeking to change policy where they think that they can. The interviewee continued:

So it is a case of its [sic] better to say something rather than nothing? I kind of twist it in a way. I do try and say things which the results say to me, because we do analysis as well as showing the results. We do highlight what the reduction [in the Footprint] would be if you take on certain policy options. We don't just stop at 'there's your report, good luck'. I'd be a bit bored if I didn't do that to tell you the truth.

In the following chapters, we explore in more detail how ideas and arguments shape policy, particularly at the local level where some of the most innovative work on the Ecological Footprint has taken place. Whilst the rational model is empirically weak it continues to hold a fascination for Footprint practitioners and those they seek to influence in government. In practice, though, knowledge is not simply used to help solve problems; it is also used strategically to help structure problems and solutions (Hertin et al. 2009). Chapter 2 argues that the Cardiff Ecological Footprint was partially successful in making use of data in an instrumental fashion as it tried to address contemporary policy issues. In Chapters 3 and 4 we explore the broader, more strategic context in which knowledge was being used. In these two chapters we look at the numerous local Ecological Footprint studies, all of which began to add to the credibility to the tool. At the same time, there was growing academic interest in the Footprint, and we chart the rise and fall of Footprint papers in academic journals. Together these practitioner and academic knowledge bases reinforced one another and could combine with other ideas (for example, the Carbon Footprints, debates on environmental limits) to help shape the policy environment (Dunlop 2014; Weiss 1995; Haines-Young and Potschin 2014).

\section{Ecological Footprint and Sustainability Indicators}

The Ecological Footprint has become increasingly popular as an indicator of environmental sustainability. As previously discussed, the Footprint has been adopted by the Welsh Government as one of 
its headline sustainability indicators. The literature on sustainability indicators has blossomed in recent years. Policy makers, researchers, citizens and environmental groups have all been keenly interested in finding out whether or not units of government or organisations are becoming more or less sustainable over time. As the UK Sustainable Development Commission (2008) has noted: 'Indicators are an effective means of quantifying and measuring progress towards sustainable development'. Whilst it is undoubtedly true that indicators can help to measure progress, their use in practice is more complex. The Ecological Footprint provides a good example of the multifaceted nature of some indicators: the Footprint can serve different purposes for different audiences. At times, both the purpose of the Ecological Footprint and the interpretation of the data which it produces can be contested, and so our perspective on the Footprint is unlikely to remain constant. Indeed, it is one of the reasons why in this book we have analysed the Ecological Footprint in an organisational context (see Chapter 2).

For their proponents, environmental or sustainability indicators can 'measure, simplify and communicate important issues and trends' (Department of the Environment, Transport and the Regions 2000, p. 5). Their development has been called for at all levels of government, from the international stage, through Agenda 21 to national and local governments. In recent years there has been a proliferation of work on sustainability indicators and its reporting. The debate about sustainability indicators has involved many disciplines, for example ecological economics (Hezri and Dovers 2006). However, it has also been noted that when put into practice, sustainability indicators are 'socially constructed policy instruments' (Astleithner and Hamedinger 2003).

There are many different types of indicator. A useful and widely noticed classification has been offered by (Brugmann 1997):

- Integrating indicators or indexes, to portray linkages between economic, social and environmental phenomena.

- Trend indicators, linked to targets and thresholds.

- Predictive indicators, relying upon mathematical forecasting models or, alternatively, conditional indicators using 'if-then' scenarios to estimate future conditions. 
- Distributional indicators, measuring intergenerational equity and specifying local, upstream and downstream effects through the use of highly disaggregated data.

- Depending upon the framework applied, condition-stressresponse indicators that provide simple causal models for local conditions. (Brugmann 1997, p. 62; based on Maclaren 1996, p. 186)

The growth of sustainability indicators has reflected a wider concern to measure performance. Trends in the organisation of national, regional and local governments to contract out services or to work with external bodies has led to much greater attention being given to the setting of targets, measuring performance and providing rewards (or penalties). So a sustainability indicator, like any other indicator, is 'a policy-relevant variable that is specified and defined in such a way as to be measurable over time and/or space ... [T] he key feature of an indicator is that measurement can take place and this, in turn, allows comparison' (Astleithner et al. 2004, p. 8).

In addition, indicators have been seen by some as a 'green herring', signifying a focus on measurement rather than action (MacGillivray 1998, p. 93). Despite this, the view that 'at the local level, indicators are ideally suited for performance measurement' (Brugmann 1997, p. 59) is becoming increasing popular (Hemphill et al. 2004, p. 726). Whilst such indicators 'are not themselves "the answer" ... they can lead us to better answers if they provide trustworthy information about those things in life that we value' (Lawrence 1998, p. 68).

Within the literature on indicators there is widespread awareness that indicators are not neutral. The information that they provide can help to make more informed policy decisions, but assessment requires the selection and weighing of criteria. There is, thus, much discussion of the methodologies to be used in the development of indicators, technical debates around what is (or is not) being measured, and how indicators can best be used in the decision making process. We follow the approach outlined in the literature, but towards the end add two important caveats that should be borne in mind in what follows. First, indicators are social constructs in that they indicate what key groups regard as important features of sustainable development. Second, indicators are used in real-life 
contexts and so their development, interpretation and implications for action will be intertwined with patterns of urban culture and governance (Astleithner et al. 2004).

Indicators can also be used for educative purposes, to guide policy or assess performance; however, these uses often have contradictory objectives which can result in confusion (Brugmann 1997, p. 59). For example, some local governments in the UK have sought to use the Ecological Footprint as a means to guide policy development, as it appears to show the environmental pressures arising from different development strategies, and at the same time to use the Footprint to communicate with their citizens about the scale of their resource use. Whilst the Ecological Footprint may have multiple functions, its use for different purposes can be confusing since it means that data has to be presented and interpreted in different ways for diverse audiences.

However, as sustainability is a contested concept with a proliferation of operational definitions, the choice of measure will never be wholly objective or value-neutral. Consequently, there tends to be a lack of consensus about the indicators that should be used and how they should be considered (Hemphill et al. 2004, p. 726). As Owens and Cowell (2002, p. 29) have pointed out, decisions about what is 'sustainable' are inseparable from moral and political choices. Taking on board the injunction from Owens and Cowell in itself presents a range of issues about desirable ends and the ways of measuring progress towards them. It is therefore essential to remember that 'those developing indicators need to be deliberate in their choice of sources, and accept that reasonable people can disagree' (Lawrence 1998, p. 70).

From a process perceptive, it is important to keep in mind that the use of sustainability indicators can generate outcomes in many ways. These can be divided into three groups (Gahin et al. 2003, p. 662):

1. through the process of developing the indicators;

2. by communicating (publishing and distributing) the indicators;

3. by action arising from the development of the indicators.

Table 1.1 provides a summary of the different areas of applicability of sustainability indicators. 
Table 1.1 Areas of applicability of sustainability indicators

\begin{tabular}{lll}
\hline Administrative context & Type of analysis & Practical application \\
\hline Information and debate & $\begin{array}{l}\text { Individual/household } \\
\text { evaluation }\end{array}$ & $\begin{array}{l}\text { In education } \\
\text { As an element of } \\
\text { environmental } \\
\text { protection work } \\
\text { Publication on municipal } \\
\text { home page }\end{array}$ \\
& & In annual reports \\
Political guidance & National benchmarking & In municipal planning \\
& Trend analysis & reports \\
& Identifying priorities & Community strategies \\
across sectors & Performance & \\
measurement & Impact assessment & Incorporation in existing \\
sdministrative & & systems of impact \\
guidance & & administrative procedure \\
\hline
\end{tabular}

Sources: Based on Aall and Norland (2005, p. 33), Bond (2002), Brugmann (1997).

\section{THE ECOLOGICAL FOOTPRINT AS A METAPHOR}

Cohen (2011) has argued that discursive entrepreneurs invoke new imagery that reframes challenges. The Ecological Footprint brings together two unrelated terms: (1) 'ecological', with its suggestion of biodiversity, management and fragility; and (2) the 'Footprint' - a human mobility activity - to give an impression of how people's actions have ecological consequences. For instance, at the launch of Wales's second Ecological Footprint report in Cardiff (May 2005) one of the keynote speakers vividly illustrated the power of the Footprint as a metaphor: 'I like the Footprint (stamps the floor repetitively), because that's exactly what we're doing to the Earth every day' (environmental NGO; quoted in Collins et al. 2009, p. 1709). Here the Ecological Footprint is being used as a conceptual metaphor: 'a simple set of relationships ... [that helps in] communicating more complex analogous concepts' (Raymond et al. 2013, p. 537). 
By symbolically asserting that our ecological resource use is a Footprint, we begin to think of how our decisions on consumption our Footprint - can have environmental impacts. In doing so, we begin to make connections between the ways in which we live our lives and the environmental consequences that arise from our lifestyle decisions. At a political level, metaphors work by bringing together what may otherwise have been diverse constituencies and fostering a collective understanding of potential courses of action (Cohen 2011). Similarly Larson (2011) reminds us that metaphors are performative; they do something. As Larson $(2011$, p. 8) goes on to explain:

[metaphors] influence our conception of the world, they catalyze particular outcomes. They dramatically affect our world views, which is not just our view of the world but also our way of living within it. Thus, the metaphors we select have very real outcomes in the constitution of culture and the political realm.

One reason why the Ecological Footprint works well as a metaphor is that the multiple meanings that can be attached to it provide a variety of messages for action. For example, the Ecological Footprint may enable us to think about inequalities of consumption as some individuals and nations have much higher Ecological Footprints than others, and so proposals to promote greater equity become attractive. Alternatively the Ecological Footprint can provide connections to how consumption in one place may have environmental consequences in another, so that a connection is made between local consumption and the global environment. Or the Ecological Footprint may suggest the finiteness of resource availability on the Earth so that the focus moves to efforts to reduce demands upon the Earth's resources. Throughout any discussions of the Ecological Footprint it is anthropocentric (the image is of a human footprint) and the interest is in human resource demand and the impacts of depleting resources upon human welfare. These different interpretations of the Ecological Footprint show how metaphors 'both highlight and hide' (Larson 2011, p. 209). Metaphors provide only partial understandings (Raymond et al. 2013, p. 537) and the Ecological Footprint privileges some features of environmental management such as resource consumption, whilst marginalising others such as social welfare. 
Metaphors can be particularly powerful in environmental policy as they help to interpret the natural world. As we have seen in the discussion above on the MSF, the Ecological Footprint rose quickly to public policy prominence, and one of the reasons why it was able to do so is because of its wide-ranging appeal. Larsson (2011, p. 7) has argued that:

A metaphor must be both accurate and comprehensible if people are to understand and embrace it. And because scientists and non-scientists live in a similar bodily and cultural context, well chosen metaphors appeal to both audiences. Whether from embodied or cultural sources, metaphors provide a remarkable way for scientists to describe their findings to others, including colleagues, scientists in other disciplines, and even non-scientists.

As the Ecological Footprint moved up public policy agendas in central and local governments, it inevitably marginalised other ideas such as Environmental Space. Whilst the Ecological Footprint may not have been as conceptually or methodologically robust as Environmental Space (see Hille 1997), it proved to be the politically more attractive. This is at least partly due to its power as a metaphor (Raymond et al. 2013).

Interest in analysing metaphors and their meaning has grown markedly in recent years. According to Low et al. (2010, pp. vii-viii), there is now widespread agreement that metaphors are important for the communication of abstract ideas, and that they have an ideological role; they help privilege some ideas over others. For metaphor researchers, much attention is now being given to how people use metaphors, such as the way in which advocates of the Ecological Footprint can use it to communicate scientific knowledge about resource consumption. Clearly, claims to scientific knowledge still count for much in policy arenas, and certainly in the environmental field where claims for problems and solutions are based on scientific expertise. For the Ecological Footprint to be able to make scientific claims enhances its credibility and the way in which it can contribute to policy debates. Work on the Ecological Footprint, particularly by its advocates, makes much of the science behind the concept (see, for example, Barrett 2001; Barrett et al. 2005a; Borucke et al. 2013; Galli et al. 2007; Lenzen et al. 2007; Wackernagel et al. 1999, 2004b). Raymond et al. (2013) claim that the Ecological Footprint is a less scientific metaphor than, say, 'the 
war against invasive species', because it originates outside of environmental science. Nevertheless, as a metaphor to communicate the scale of resource consumption and to persuade a variety of actors, from citizens to NGOs, officials and politicians, of the need for action, the Ecological Footprint has proved remarkably effective. Indeed, an indication of the Footprint's effectiveness as a metaphor is that it has been applied to a number of other environmental tools to give them legitimacy. So we now have Carbon Footprints and Water Footprints.

\section{BOOK STRUCTURE}

We have been fortunate to be both participants and observers of developments in the Ecological Footprint. We first became involved in research on the Ecological Footprint in the early 2000s. There was much interest in the Ecological Footprint in Wales and we were then given the opportunity to work on a project investigating Cardiff's Ecological Footprint. From that time on we have been involved in thinking about new applications for the Ecological Footprint, such as for major sports events and festivals, exploring how the Ecological Footprint may or may not become embedded in an organisation (Cardiff Council), and been involved in a number of Ecological Footprint conferences. During this time we have taken the opportunity to talk to fellow academics, government officials, Ecological Footprint practitioners, NGOs and GFN staff. Many of these have been involved in multiple interviews or discussions. This has allowed us to build up a rich data source of key person interviewees. We have made use of these discussions and interviews throughout the book, as they have assisted enormously in our understanding of the Ecological Footprint. The Ecological Footprint community at a national and international level is relatively small. All of our interviewees have been anonymised. As well as interviews and discussions, Chapter 6 also makes use of an online survey that we conducted of GFN partners. The survey was conducted at a time of growth in Ecological Footprint studies. The survey provides a valuable insight into how those who work at a national level come together in an international network to further their interest in policy applications and methodological improvements. 
We regard the Ecological Footprint as multifaceted - it has a policy development dimension, it is a communication tool and helps to frame environmental knowledge, and it has witnessed a number of methodological developments and novel applications and throughout the book have sought to portray it in that way. In this chapter we have set the political and institutional context for the Ecological Footprint.

In Chapter 2, we take these ideas forward and examine how the Ecological Footprint has contributed to policy development. Our analysis concentrates on Cardiff, where we can draw upon our longitudinal data. This enables us to provide detailed insights into how the Ecological Footprint fares in an organisational setting. The approach to Ecological Footprinting in Cardiff has often been acclaimed for its efforts to mainstream environmental thinking.

Chapter 3 critically reviews the process developed to measure Cardiff's Ecological Footprint and the results that arose. Information on the size of Cardiff's Footprint led to further work on how that should be interpreted and what implications it may have for future policy development. To provide further context for the Cardiff study, its results are compared to other cities. Cardiff, like a number of other UK cities, has shown itself keen to engage with the Ecological Footprint.

In Chapter 4 we explore the reasons behind the UK's interest in Ecological Footprint studies. Key factors that we consider include funding opportunities which enabled the growth of consultancies and academic institutes, as well as the efforts of environmental NGOs such as WWF. The UK experience is contrasted with that of Australia, where with a much less favourable funding environment there have nevertheless been important initiatives undertaken to promote the Ecological Footprint. One of the more remarkable features of the Ecological Footprint has been the way in which academics and practitioners have promoted innovative applications.

In Chapter 5, we critically examine some of the key novel applications, such as Footprint calculators, and how the Ecological Footprint has been used to communicate environmental information. These innovations in the use of the Footprint have done much to ensure that debates on the Ecological Footprint have been so vibrant.

Chapter 6 provides an analysis of GFN, the key body that brings together Footprint producers and users and seeks to establish a 
standard that can be applied to Ecological Footprint studies. Standard-setting emerges as a key means to establish the credibility of the Ecological Footprint. The chapter also reports on a survey of GFN partners and shows that they have diverse interests in the Ecological Footprint, and that once attention begins to wane in the Ecological Footprint some partners also lose interest, which begins to undermine the credibility of the Footprint.

Finally, in Chapter 7 we cover three themes: the changing status of the Ecological Footprint; the growth of other Footprint tools, especially that for carbon; and how the Footprint contributes to our understanding of environmental knowledge.

\section{NOTE}

1. Our data collection strategy and reporting of interview material is discussed later in the chapter. 


\section{APPENDIX}

\section{Table 1A.1 Timeline of key Ecological Footprint events, activities and publications}

Year Events, activities, publications

1992 Professor William (Bill) Rees, School of Community and Regional Planning at the University of British Columbia, publishes first academic article 'Ecological footprints and appropriated carrying capacity: what urban economics leaves out', in the journal Environment and Urbanisation.

1994 Mathis Wackernagel, PhD student at University of British Columbia (under the supervision of Professor Rees) defends his PhD thesis, 'Ecological Footprint and appropriated carrying capacity: a tool for planning toward sustainability'.

1996 Wackernagel and Rees co-author first book on the Ecological Footprint, Our Ecological Footprint: Reducing Human Impact on the Earth.

UK Ecological Footprint consultants Best Foot Forward (BFF), develops $\mathrm{EcoCal}^{\mathrm{TM}}$, the first computer based calculator to measure personal and household Ecological Footprints.

1999 BFF develops Regional Stepwise, the first regional Ecological Footprint calculator and undertakes the first Footprint study of a local government area in the UK (Isle of Wight).

2000 WWF publishes its first Living Planet Report on the planet's available biocapacity and Ecological Footprint.

Wackernagel co-authors book with Chambers and Simmons (co-founders of BFF): Sharing Nature's Interest: Ecological Footprints as an Indicator of Sustainability (Chambers et al. 2000).

Australian Conservation Foundation (ACF) publishes Natural Advantage. A Blueprint for a Sustainable Australia (Krokenberger et al. 2000), outlining 32 reforms needed for a sustainable environment and to reduce Australia's Ecological Footprint.

2001 World Wide Fund for Nature (WWF) Cymru (Wales) commissions first Ecological Footprint study of Wales.

Wales adopts the Ecological Footprint as one of five headline indicators for sustainability, and is the first country to formally monitor and report on changes.

UK Ecological Footprint consultant Stockholm Environment Institute - York (SEI-York), undertakes its first Ecological Footprint studies (Liverpool and York).

2002 Global Footprint Network (GFN) is launched, and formally established as a non-profit organisation in 2003.

WWF publishes Living Planet Report 2002.

WWF UK publishes Ecological Footprints: A Guide for Local Authorities (Bond 2002), explaining what an Ecological Footprint is, its calculation and value as a policy and environmental awareness tool. 
Year Events, activities, publications

The Environmental Protection Authority Victoria (EPA Victoria), Australia, invites Mathis Wackernagel, Executive Director of GFN, to the state of Victoria to facilitate training workshops and meetings in Melbourne and Sydney to help promote the Ecological Footprint. Two further visits are arranged between 2002 and 2007.

The Scottish Executive (UK) commissions Ecological Footprint study of Scotland's five main cities.

2003 WWF UK secures funding from Biffa Award to undertake Ecological Footprint studies in Wales and Scotland.

BIFFA Award publishes with SEI-York and WWF, the first material flow analysis and Ecological Footprint study of a UK region (South East of England) (Barrett et al. 2003).

$200430+$ organisations join the GFN Partner Network.

Wackernagel and Rees's book, Our Ecological Footprint: Reducing Human Impact on the Earth, is published in Japanese.

GFN collaborates with WWF on WWF's Living Planet Report 2004.

$200550+$ organisations are now part of the GFN Partner Network.

GFN establishes two committees (National Accounts and Standards), comprised of members from the network's partner organisations. Standards are drafted and made available for public comment.

GFN launches its Ten-in-Ten campaign to institutionalise the Ecological Footprint in at least ten nations by 2015 . GFN is in active dialogue with 24 countries likely to be early adopters of the Ecological Footprint.

GFN develops the first set of Footprint Standards for Ecological Footprint applications and its communication.

GFN collaborates with WWF on:

Europe 2005: The Ecological Footprint (Wackernagel et al. 2005b), the first Ecological Footprint study of Europe's 25 nations. The Ecological Footprint was subsequently included in Europe's Sustainable Development Strategy;

Asia-Pacific 2005: The Ecological Footprint and Natural Wealth (Wackernagel et al. 2005a), which reports on the Ecological Footprints of more than 20 countries.

GFN with the International Institute for Sustainable Development (IISD) conducts an Ecoloigcal Footprint study of Canadian Provinces as part of the Canadian Index of Well-Being.

GFN with support from the European Environment Agency (EEA) completes a major update of the National Footprint Accounts (2005 edition).

EEA publishes its report (with contributions by GFN partners, SEI-York and New Economics Foundation), The European Environment - State and Outlook 2005 (European Environment Agency 2005), which features the Ecological Footprint. 
Year Events, activities, publications

GFN with WWF-UK, BFF and SEI-York collaborate on a One Planet Business project that measures the ecological footprint of major business sectors.

EPA Victoria (Australia) commissions GFN and ISA at the University of Sydney to undertake the first Ecological Footprint study of the Australian state of Victoria, EPA Victoria (2005), The Ecological Footprint of Victoria: Assessing Victoria's Demand on Nature.

EPA Victoria with GFN and VicUrban (an urban development agency), and the Centre for Design at RMIT, assesses the Ecological Footprint of a 'green development' in the state of Victoria.

CSIRO (Australia) publishes Balancing Act, the first triple bottom-line analysis of Australian economy (study undertaken by ISA at the University of Sydney).

CSIRO also funds the development of triple bottom line $\left(\mathrm{TBL}^{3}\right)$ software tool later marketed as 'BottomLine' ${ }^{3}$.

$200675+$ organisations are now part of the GFN Partner Network.

Biffa Award commissions SEI-York and others to undertake the Ecological Budget UK project. Project outputs include: a material flow analysis and Ecological Footprint study of the UK and several UK regions, the policy software tool REAP, a Sustainable Production and Consumption network, and a website. SEI-York also develops a suite of REAP tools for specific economic sectors (education, health, tourism).

WWF UK publishes two reports:

Ecological Footprints: Taking the First Step, A 'How to' Guide for Local Authorities (Bond and Matthews 2006), a guide for local authorities on how to undertake an Ecological Footprint study;

Ecological Footprints: The Journey so Far, Lesson Sharing and Case Studies of Local Authorities in the United Kingdom (Ross 2006), which provides a summary of key lessons learnt from eight UK Ecological Footprint projects.

GFN launches its own online personal Ecological Footprint calculator.

GFN organises first Footprint Forum, a conference event for GFN partner organisations at Siena (Italy) which is attended by 200 Ecological Footprint practitioners and supporters. GFN launches first approved Footprint Standards at the Forum.

GFN collaborates with WWF on Africa's Ecological Footprint: Human Well-Being and Biological Capacity (GFN 2006c).

GFN collaborates with WWF on WWF's Living Planet Report 2006.

GFN launches its Earth Overshoot Day campaign. In 2006, Earth Overshoot Day was estimated to be 6 October.

Japan's Ministry of the Environment incorporates the Ecological Footprint into its Basic Environment Plan, and agrees to work with GFN to conduct a review of Japan's National Footprint Accounts. 
Year Events, activities, publications

$200780+$ organisations are now part of the GFN Partner Network.

The ESRC BRASS Research Centre at Cardiff University (UK) with GFN organises and hosts the first academic conference on the Ecological Footprint in Cardiff. Over 200 participants attend from 112 organisations in 23 countries.

Wales pledges to reduce its per capita Ecological Footprint to the global average available within one generation as part of its One Planet: One Wales campaign.

Scotland includes the Ecological Footprint in its National Performance Framework.

UK Ecological Footprint consultants, BFF, develops Footprinter, a Carbon and Ecological Footprint calculation and management tool for businesses. Specialised versions are developed for different service and business sectors.

WWF UK publishes Ecological Footprint results for 60 British cities, Ecological Footprint of British City Residents (Calcott and Bull 2007).

UAE launches Al Basma Al Beeiyah Initiative, its Ecological Footprint initiative, and commissions GFN to undertake an in-depth study to better understand its Ecological Footprint and improve the accuracy of its calculation.

ACF and ISA at the University of Sydney, launch first interactive Consumption Atlas showing household GHG emissions and Ecological Footprints for various geographical areas across Australia.

ISA, University of Sydney launches its $\mathrm{TBL}^{3}$ sustainability reporting tool which incorporates Ecological Footprint data.

GFN collaborates with WWF on:

Canadian Living Planet Report 2007 (WWF and GFN 2007);

Europe 2007: Gross Domestic Product and Ecological Footprint (WWF 2007).

$2008100+$ organisations are now part of the GFN Partner Network.

Welsh Assembly Government with SEI-York publishes the results from its third Ecological Footprint study of Wales, Wales' Ecological Footprint: Scenarios to 2020 (Dawkins et al. 2008).

EPA Victoria commissions second Ecological Footprint study of Victoria.

GFN and EPA Victoria are signatories to a Sustainability Covenant to further promote the Ecological Footprint in Victoria and Australia. The Ecological Footprint is used as an indicator in Victoria's first comprehensive State of the Environment Report (Commissioner Environmental Sustainability Victoria 2008). Australia's first personal Ecological Footprint calculator is launched.

GFN collaborates with WWF on:

2010 and Beyond: Rising to the Biodiversity Challenge (WWF and GFN 2008a); Report on the Ecological Footprint of China (WWF and GFN 2008c);

Africa: Ecological Footprint: and Human Well-being (second report) (WWF and GFN 2008b); 
Year Events, activities, publications

Hong Kong Ecological Footprint Report 2008: Living Beyond our Means (Hong Kong's first Ecological Footprint report) (WWF Hong Kong 2008).

GFN collaborates with WWF on WWF's Living Planet Report 2008.

GFN publishes with Confederation of Indian Industry, India's Ecological Footprint: A Business Perspective.

GFN publishes The Ecological Footprint Atlas 2008, a summary of the Ecological Footprint and biocapacity from the 2008 Edition of National Footprint Accounts (covering 201 countries).

GFN Partners, BFF, SERI Ecologic, Envirocentre publish Potential of the Ecological Footprint for Monitoring Environmental Impacts from Natural Resource Use (Best et al. 2008).

Switzerland adopts the Ecological Footprint as an indicator, and incorporates it into its Sustainability Development Plan.

Finland includes the Ecological Footprint in its suite of sustainability indicators, and collaborates with GFN to improve its national footprint accounts.

2009 EUREAPA software developed through One Planet Economy Network (EU 7th Framework Programme for Research and Development. Project involved eight international partners (including SEI-York, WWF UK and GFN), and involves developing a 'Footprint family' of footprint indicators: Ecological, Carbon and Water.

Ecuador incorporates the Ecological Footprint into its National Plan for Good Living and commits to reversing its ecological deficit by 2015 .

UAE as part of the Al Basma Al Beeiyah Initiative, its Ecological Footprint initiative, collaborates with GFN to develop a policy scenario to test various energy policies.

GFN publishes:

Africa FactBook 2009;

The Ecological Footprint Atlas 2009, a summary of the Ecological Footprint and biocapacity from the 2009 Edition of National Footprint Accounts (covering 201 countries).

GFN publishes with WWF, Japan Ecological Footprint Report 2009: Maintaining Well-being in a Resource Constrained World (Wada et al. 2009), Japan's first Ecological Footprint report.

$201090+$ organisations are now part of the GFN Partner Network.

GFN publishes:

The Ecological Footprint Atlas 2010, a summary of the Ecological Footprint and biocapacity from the 2010 Edition of National Footprint Accounts (covering 201 countries);

The Ecological Wealth of the Nations report.

GFN collaborates with WWF on WWF Hong Kong's Hong Kong Ecological Footprint Report 2010. 
Year Events, activities, publications

GFN collaborates with WWF on WWF China's China Ecological Footprint Report 2010.

GFN collaborates with WWF on WWF's Living Planet Report 2010.

GFN collaborates with GIZ (Germany) WWF and others on A Big Foot on a Small Planet? (Amend et al. 2010).

The UN Development Programme includes the Ecological Footprint as an indicator for assessing lasting human progress.

Sao Paulo adopts the Ecological Footprint as a key sustainability indicator.

Luxembourg's Council for Sustainable Development and the Foreign Ministry adopt the Ecological Footprint.

Wackernagel and Beyers publish Der Ecological Footprint: Die Walt neu Vermessen (German), The Ecological Footprint: The World Re-measured (English).

$201179+$ +organisations are now part of the GFN Partner Network.

GFN collaborates with Landcare Research and Massey University (New Zealand) on An Analysis of New Zealand's Ecological Footprint as Estimated by the Global Footprint Network: An Update (Andrew and Forgie 2011);

GFN collaborates with San Francisco Planning \& Urban Research Association on Ecological Footprint Analysis: Francisco-Oakland-Fremont, CA Metropolitan Statistical Area (Moore, 2011);

GFN collaborates with UNDP on Resource Constraints and Economic Performance in Eastern Europe and Central Asia (GFN 2011).

Costa Rica features the Ecological Footprint in its annual State of Nation report.

Switzerland adopts the Ecological Footprint as an indicator in its Sustainable Development Report 2012 (Willi et al. 2011).

2012 GFN collaborates with WWF on:

Türkiya'nin Ekolojik Ayak İzi Raporu (Turkey Ecological Footprint Report) (WWF Türkiye);

the first Ecological Footprint study of a Brazilian city, The Ecological Footprint of Camp Grande and its Family Footprint (Becker et al. 2012);

The Ecological Footprint of São Paulo - State and Capital and the Footprint Family (WWF Brazil 2012);

Japan Ecological Footprint Report 2012 (Poblete et al. 2012);

WWF's Living Planet Report 2012;

WWF China's China Ecological Footprint Report 2012.

GFN publishes:

Mediterranean Ecological Footprint Trends (Galli et al. 2012b);

A Measure for Resilience 2012 Report on the Ecological Footprint of the

Philippines. 
Year Events, activities, publications

GFN publishes with the Arab Forum for Environment and Development, Arab Environment: 5 Survival Options Ecological Footprint of Arab Countries (Saab 2012).

The Philippines is the first country in Southeast Asia to adopt the Ecological Footprint.

Indonesia officially adopts the Ecological Footprint.

GFN's Ten-in-Ten campaign reaches its goal three years ahead of schedule.

$201368+$ organisations (from across six continents) are now part of the GFN partner network.

GFN collaborates with US Environmental Protection Agency on The Ecological Footprint and Biocapacity of California (Moore et al. 2013).

GFN collaborates with WWF on Hong Kong Ecological Footprint Report 2013 (WWF Hong Kong 2013).

GFN collaborates with Laguna Lake Development Authority on Philippines 2013 Ecological Footprint Report: Resorting Balance in Laguna Lake Region (GFN 2013b).

Note: Countries in bold are part of the Global Footprint Network's Ten-in-Ten campaign. 